\title{
Acute experimental Trypanosoma cruzi infection: establishing a murine model that utilises non-invasive measurements of disease parameters
}

\author{
Diana Rodrigues da Silva, Solange Lisboa de Castro, Monique Castro da Silva Alves, \\ Wanderson da Silva Batista, Gabriel Melo de Oliveira/ ${ }^{+}$
}

Laboratório de Biologia Celular, Instituto Oswaldo Cruz-Fiocruz, Av. Brasil 4365, 21045-900 Rio de Janeiro, RJ, Brasil

\begin{abstract}
Trypanosoma cruzi infection has a large public health impact in Latin American countries. Although the transmission rates via blood transfusions and insect vectors have declined sharply in the past 20 years due to policies of the Southern Cone countries, a large number of people are still at risk for infection. Currently, no accepted experimental model or descriptions of the clinical signs that occur during the course of acute murine infection are available. The aim of this work was to use non-invasive methods to evaluate the clinical signs of Balb/c mice infected with the $Y$ strain of T. cruzi. The infected mice displayed evident clinical changes beginning in the third week of infection. The mice were evaluated based on physical characteristics, spontaneous activity, exploratory behaviour and physiological alterations. We hope that the results presented in this report provide parameters that complement the effective monitoring of trypanocidal treatment and other interventions used to treat experimental Chagas disease.
\end{abstract}

Key words: Trypanosoma cruzi - clinical signs - non-invasive parameters - murine model

In Latin America, the transmission rates of the protozoan parasite Trypanosoma cruzi, the causative agent of Chagas disease, have steadily declined due to a series of multinational initiatives aimed at both the interruption of vector transmission (by Triatoma infestans) and the practice of screening blood donors (Schofield et al. 2006, Dias et al. 2008, Coura \& Borges-Pereira 2010). The incidence of Chagas disease has dropped from 700,00040,000 new cases per year and the annual number of deaths has fallen from more than 45,000-12,500 (Moncayo \& Silveira 2009). However, the epidemiology of the disease has become more complex due to the presence of multiple vectors and reservoirs and the added effects of geopolitical, economic and ecological upheaval (Coura 2006, Beltrão et al. 2009, Lescure et al. 2010).

The eminent Brazilian scientists Carlos Chagas and Emanuel Dias have described the basic features of $T$. cruzi infection in mice (Chagas 1909, Dias 1934). Depending on the mouse lineage and parasite strain used for the infection, there are subtle differences in the kinetics of parasitaemia, the intensity of the parasite load and the mortality rates during the course of infection. Until now, there has been no consensus model for the various aspects of the disease due to the heterogeneity of the results obtained from different studies (AraújoJorge \& De Castro 2000). This obstacle, along with others, hampers a reproducible comparison of the ex-

Financial support: FAPERJ, CNPq, FIOCRUZ

+ Corresponding author: gmoliveira@ioc.fiocruz.br

Received 3 June 2011

Accepted 11 January 2012 perimental infection to the human disease as it occurs in nature (Coura 2000).

Many aspects of T. cruzi infection have been studied using mouse models, including the infectivity of various tissues (Lenzi et al. 1996), the presence of cardiac inflammatory lesions (Marinho et al. 1999, Andrade et al. 2006, Pavanelli et al. 2010), the disturbance of the cardiac electrical conduction system (Eickhoff et al. 2010), acute kidney injury (AKI) (Oliveira et al. 2009b) and the efficacy of drug treatment regimens (Soeiro et al. 2009). However, there are significant differences between the natural disease and experimental models. The disease models often hinge on the description of specific clinical symptoms observed during the course of an experimental infection. Balb/c mice are susceptible to T. cruzi infection (Araújo-Jorge \& De Castro 2000) and we have previously reported important alterations in this mouse lineage during infection with the T. cruzi Y strain based on electrocardiographic and arterial pressure parameters (Oliveira et al. 2009a). In addition to the non-invasive cardiac evaluation, we also observed AKI in infected mice (before the parasitaemia peak and the onset of inflammatory myocardial damage), which was independent of parasite load (Oliveira et al. 2009b).

In this context, the aim of this study was to use noninvasive methods to monitor the clinical signs (disease model) of Balb/c mice infected with $T$. cruzi. Acutely infected mice showed evident clinical changes beginning in the third week of infection. The mice were evaluated based on physical characteristics, spontaneous activity, exploratory behaviour and physiological alterations. We hope that the data obtained in this study will provide helpful parameters to monitor the efficacy of trypanocidal chemotherapy and other treatments for experimental Chagas disease. 


\section{MATERIALS AND METHODS}

Animals - Eight-week-old specific pathogen-free male isogenic BALB/c mice were obtained from the Oswaldo Cruz Foundation (Fiocruz) animal facility. The mice were housed at the Department of Animal Experimentation, Oswaldo Cruz Institute, Fiocruz, and maintained under stable temperature conditions with $12 \mathrm{~h}$ light/dark cycles. The mice were housed in the facility for at least one week before T. cruzi infection. All procedures were performed in accordance with the guidelines established by the Fiocruz Committee of Ethics for the Use of Animals (protocol 020/08). The number of animals used in each experimental group is presented in the Figure legends.

Parasites and infection - The T. cruzi $\mathrm{Y}$ strain was passaged in vivo in outbreed Swiss Webster mice and trypomastigote forms were isolated from the bloodstream as previously described (Araújo-Jorge 1989). The parasites were resuspended in phosphate-buffered saline (PBS) and counted using a haemocytometer. The concentration of the inoculum was adjusted to $5 \times 10^{3}$ parasites $/ \mathrm{mL}$. The infection was performed with $200 \mu \mathrm{L}$ of this suspension $\left(1 \times 10^{3}\right.$ parasites) through intraperitoneal injection (Inf group). The uninfected control mice (NI) received only PBS.

Parasitaemia, weight loss and cumulative mortality - Parasitaemia was determined daily from six-15 days post-infection (dpi) using the Pizzi-Brener method (Brener 1962). The body weight was evaluated weekly from 0-30 dpi. The mortalities were noted daily and the index of cumulative mortality was calculated at $30 \mathrm{dpi}$.

Physical characteristics and food consumption The animals were physically inspected daily during the course of the infection. The following parameters were evaluated: body posture, skin integrity (injury and/or peeling), fur appearance (piloerection, dull fur and focal or diffuse alopecia), infestation by ectoparasites and the presence of clinical symptoms associated with secondary bacterial infections, such as dermatitis and conjunctivitis. The changes were recorded daily with video and photographs of each animal. The consumption of food and water was measured daily (beginning 1 week prior to infection) by calculating the differences between the weight/volume offered to animals $(250 \mathrm{~g} / 250 \mathrm{~mL})$ and the amounts of food and water remaining in each cage after $24 \mathrm{~h}$. The individual consumption amounts were estimated using the following formulae:

Cons $_{\text {total }}=$ weight/volume added - weight/volume after $24 \mathrm{~h}$ $\mathrm{Cons}_{\text {ind }}=\mathrm{Cons}_{\text {total }}$ /number of animals per cage

Ethogram - Using an adaptation of the previously reported mouse phenotype characterisation method (Keeney et al. 2006, Kalueff et al. 2007), a set of behavioural activities, including grooming, immobility and rearing (vertical lifting), was registered. The ethograms were produced daily for each animal from $0-30$ dpi. The number of behavioural activities (number of events) in an open field test (interval of $5 \mathrm{~min}$ ) and the mean value for each experimental group (NI and Inf) are expressed in the ethogram.
Motor and exploratory activity - To further characterise the spontaneous activity of the mice, we used the video-tracking tool Noldus EthoVision XT6 (Noldus Information Technology, Leesburg, The Netherlands). The arena was defined as 12 rectangles divided into lateral and central areas. In the total arena, the rectangles were calibrated to contain equal areas to ensure the consistency of the parameters through which the Noldus EthoVision XT6 apparatus detected transitional mouse movements. This analysis was used to measure the following parameters: (i) locomotor activity, defined as covered distance $(\mathrm{cm})$ and average velocity $(\mathrm{cm} / \mathrm{s})$, and (ii) exploratory activity, defined as the frequency of travel to the central region (number of events) per $5 \mathrm{~min}$, which was measured daily from 0-30 dpi. The video was recorded with a camera placed $1.0 \mathrm{~m}$ away from the observation arena.

Body temperature - The body temperature of each mouse was assessed daily throughout the course of the infection (from 0-30 dpi). The temperatures were measured by physically restraining the mice and evaluating the auricular temperature with a Braun ThermoScan Digital Ear Thermometer (Braun Ind, São Paulo, BR).

Statistical analysis - The Mann-Whitney non-parametric test was used to compare the two groups (SPSS software, version 8.0) and $\mathrm{p}$ values are indicated in the Figure legends.

\section{RESULTS}

Our results demonstrated the reproducibility of the infection course in Balb/c mice infected with the $\mathrm{Y}$ strain of $T$. cruzi. The peak of parasitaemia was observed at 8 dpi, with approximately $4 \times 10^{6}$ parasites $/ \mathrm{mL}$ (Fig. 1A). A significant decrease in body weight was observed in Inf mice compared to NI animals at $21 \mathrm{dpi}(18.5 \pm 0.5 \mathrm{~g}$ vs. $23.0 \pm 0.6 \mathrm{~g}), 28 \mathrm{dpi}(17.7 \pm 0.4 \mathrm{~g}$ vs. $23.6 \pm 0.8 \mathrm{~g})$ and 30 dpi (19.1 \pm 0.6 g vs. $23.8 \pm 0.7$ g) (Fig. 1B). The cumulative mortality of Inf mice was $80 \%$ at 30 dpi (Fig. 1C).

The analysis of the physical characteristics of each mouse from 0-30 dpi is depicted in Fig. 2. The NI mice ( 0 dpi) displayed lively and bright eyes, lined and brilliant fur, good skin integrity and no signs of peeling or alopecia (Fig. 2A). During the first two weeks of infection (13 dpi), slight alterations in the fur were observed. These changes included mild piloerection, especially in the dorsal region (Fig. 2B), which increased during the second week. At 15 dpi, altered body posture was observed, which was characterised by downward-tilted ears, matted fur and an increase in piloerection (Fig. 2C). The alterations in posture and fur texture became more pronounced between 19-25 dpi. At this stage, the mice displayed a hunched posture (mainly in the thoracic region), closed eyes (conjunctivitis was detected in some individuals), peeling skin and an increase in piloerection (Fig. 2D). Animals that survived this period showed clinical signs of remission at $30 \mathrm{dpi}$ and these signs were similar to those observed during the second week of infection (Fig. 2E). At 21 dpi, the physical characteristics of immobility, prostration and social isolation became more evident (Fig. 2F).

We also measured the motor and exploratory activities of the Inf mice (Fig. 3). The motor activity was measured 
as the distance covered by each animal in a delimited arena within $5 \mathrm{~min}$ (Fig. 3A). The exploratory activity was measured based on the frequency with which each mouse inhabited the central quadrant of the arena (Fig. 3B). Before the infection, both groups displayed similar levels of motor activity (Inf animals moved 2,580 $\pm 390 \mathrm{~cm}$ and NI mice moved 2,500 $\pm 280 \mathrm{~cm}$ ) and exploratory activity (Inf mice displayed $9.1 \pm 1.8$ events and NI mice displayed $9.0 \pm 2.0$ events). Interestingly, at $1 \mathrm{dpi}$, there was a significant decrease in both motor $(1,390 \pm 320 \mathrm{~cm}$ vs. 2,250 $\pm 369 \mathrm{~cm})$ and exploratory activities $(1.0 \pm 0.4$ events vs. $9.0 \pm 1.9$ events). The motor activity of Inf mice was decreased at 4 dpi $(439 \pm 59 \mathrm{~cm})$, showed a partial recovery at $8 \mathrm{dpi}(1,890 \pm 220 \mathrm{~cm})$ and was decreased again at $10 \mathrm{dpi}(1,310 \pm 198 \mathrm{~cm})$. The lowest motor activity value was observed at $21 \mathrm{dpi}(232 \pm 23 \mathrm{~cm})$. The exploratory activity decreased steadily throughout the course of infection and at $21 \mathrm{dpi}(0.5 \pm 0.01$ events $)$ and $22 \mathrm{dpi}(0.4 \pm 0.01$ events), the animals displayed practically no curiosity.
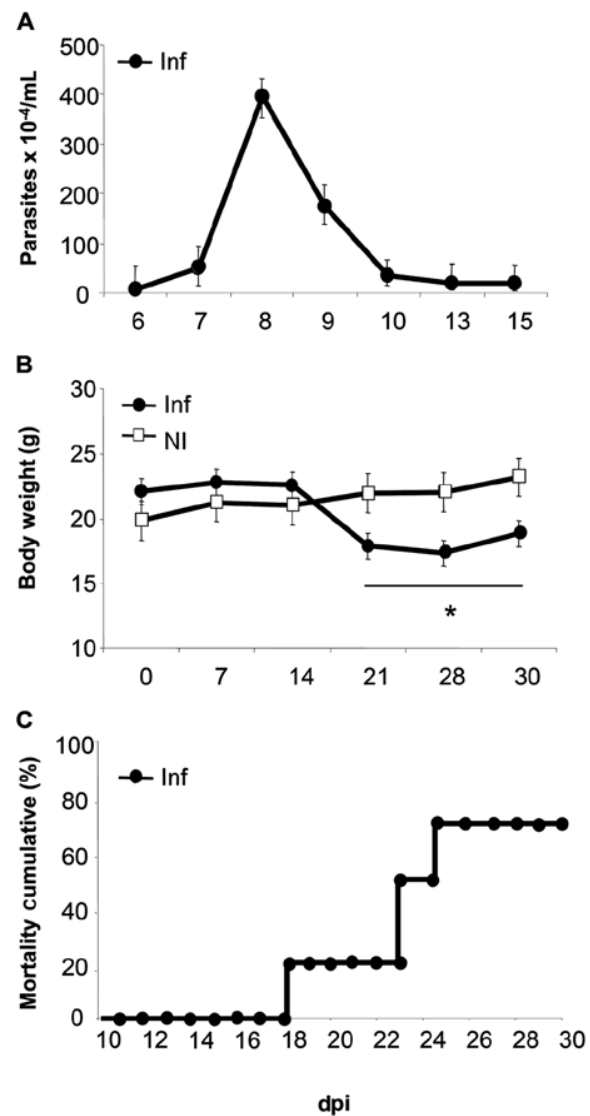

Fig. 1: parasitological parameters and body weight. Balb/c mice were inoculated by intraperitoneal injection of $1 \times 10^{3}$ parasites of the Trypanosoma cruzi $\mathrm{Y}$ strain in $200 \mu \mathrm{L}$. A: parasitaemia curve for the infected animals with a peak of $400 \times 10^{4}$ parasites $/ \mathrm{mL}$ at 8 days postinfection (dpi); B: kinetic study of body weight, showing a statistically significant decrease for the infected group after $14 \mathrm{dpi}$; $\mathrm{C}$ : curve of the cumulative mortality which reached $80 \%$ at $30 \mathrm{dpi}$. Values correspond to means \pm standard deviation of three independent experiments performed with 10 mice each; NI (white squares): non-infected group; Inf (grey circles): T. cruzi-infected group.
T. cruzi infection led to a decrease in the mobility of the mice, as monitored with video footage (Fig. 4A). There was a significant decrease in the number of rearing events (16 \pm 1.5 events), which reached minimal values at $21 \mathrm{dpi}(1.0 \pm 0.01$ events) (Fig. 4B). For grooming levels, there was a drop at $15 \mathrm{dpi}(0.9 \pm 0.01)$ and the lowest levels were reached at $21 \mathrm{dpi}(0.7 \pm 0.01)$ (Fig. 4C).

With regard to food consumption (Fig. 5), the intake levels were similar in the Inf and NI groups until 6 dpi (4.1 $\pm 0.5 \mathrm{mg}$ ). After $6 \mathrm{dpi}$, there was a decrease in the food consumption by Inf mice, which reached the lowest value at $24 \mathrm{dpi}(0.5 \pm 0.01 \mathrm{mg})$. For water intake, there was a gradual decrease in consumption by the infected animals starting at 5 dpi ( $\operatorname{Inf} 4.2 \pm 0.8 \mathrm{~mL}$ vs. NI $6.1 \pm 0.5 \mathrm{~mL}$ ), with a minimum measurement of $0.3 \pm 0.01 \mathrm{~mL}$ at $22 \mathrm{dpi}$.

Finally, the body temperature measurements were consistent with the profiles of toxaemia and circulatory shock models (Fig. 6). The body temperature of NI mice was $36.5 \pm 0.3^{\circ} \mathrm{C}$, whereas fever was detected in Inf mice beginning at $1 \mathrm{dpi}\left(37.5 \pm 0.2^{\circ} \mathrm{C}\right)$. A temperature peak occurred at $3 \mathrm{dpi}\left(38.5 \pm 0.3^{\circ} \mathrm{C}\right)$ and there was a severe temperature decrease $\left(33.0 \pm 0.4^{\circ} \mathrm{C}\right)$ at $21 \mathrm{dpi}$. The minimum body temperature of $30.5 \pm 0.3^{\circ} \mathrm{C}$ was reached at $23 \mathrm{dpi}$. The surviving animals recovered a normal body temperature at approximately $27 \mathrm{dpi}$.

\section{DISCUSSION}

There are several experimental models of $T$. cruzi infection; however, there is no single murine model that accurately recapitulates the parasitological parameters
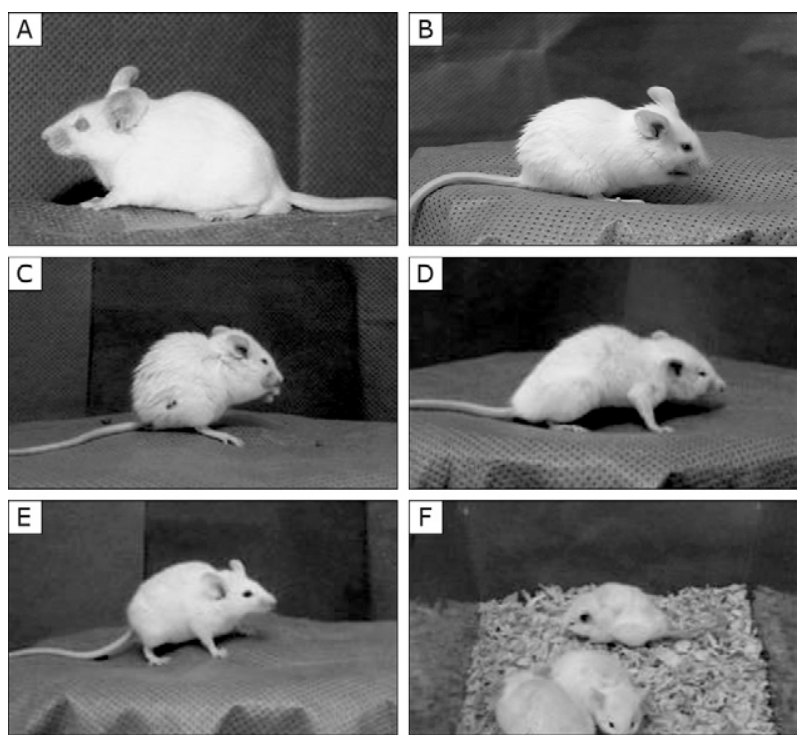

Fig. 2: physical characteristics of the animals. A: the healthy mice showed characteristics such as normal posture, lined and brilliant fur, bright eyes and erect ears; B: at 8 days post-infection (dpi), only subtle alterations in the fur were observed; C: at $15 \mathrm{dpi}$, fur alterations increased, including piloerection and alterations in the ear position; D: at $21 \mathrm{dpi}$, the animals showed prostration, piloerection and cachexia; E: at $30 \mathrm{dpi}$, the surviving animals exhibited a physical appearance similar to that observed at $7 \mathrm{dpi} ; \mathrm{F}$ : with regard to social behaviour, at 21 dpi there was social isolation and decreased mobility. 
and the pathological and clinical aspects observed in humans (Araújo-Jorge \& De Castro 2000). The development of a murine disease model using non-invasive parameters enables the translation of pathophysiologic alterations induced by the parasite into an experimental model that can be used for research.

The characteristics of the model presented in this report (Balb/c mice infected with the Y strain of T. cruzi) reproduced the observations of parasitaemia, body weight and cumulative mortality in our previous publications (Oliveira et al. 2007, 2009a, b).

Medical (or veterinary) semiology defines a clinical sign as any objective disturbance that can be perceived by the examiner for the purpose of establishing a diagnosis (Porto 2010). Several murine models of human diseases, including cancer (Kalamarides et al. 2010), asthma (Bates et al. 2009) and diabetes (Babad et al. 2010), can be found in the literature. However, studies evaluating the clinical signs of infectious diseases are mostly associated with the routine sanitary control of animal colonies (Lapchik et al. 2009). Research focusing on human behavioural disorders, such as depression and anxiety, employs murine models and non-invasive techniques, including the measurement of motor and exploratory activities, to evaluate the effectiveness of experimental therapies (Cryan \& Holmes 2005, Matsumoto et al. 2005, Taylor et al. 2010). We believe that these parameters are also useful for the clinical evaluation of our experimental model.

The results presented here demonstrate that the physical appearance and activity of mice are markedly altered during the course of acute T. cruzi infection. The altered characteristics included body posture, piloerection, fatigue, weakness, weight loss, reduction in food consump-
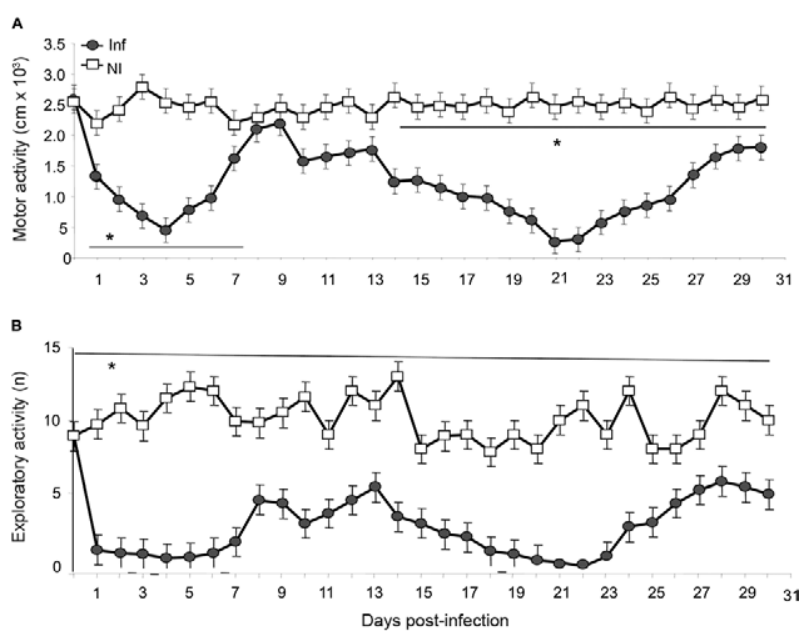

Fig. 3: physical activity. Spontaneous activity of the animals was assessed in an arena divided into central and lateral quadrants. A: motor activity was measured as the total distance covered $(\mathrm{cm})$; B: exploratory interest was measured by the number of visits (events) in the central quadrant. Values correspond to means \pm standard deviation of three independent experiments performed with 10 mice each. Asterisk means statistically significant differences between infected and control mice $(\mathrm{p}<0.05)$. NI (white squares): non-infected group; Inf (grey circles): Trypanosoma cruzi-infected group. tion and, most importantly, hypothermia. Each of these signs is characteristic of progressive cachexia (Cerami et al. 1985). Starting at one day after infection, a reduction in spontaneous physical activity and a loss of exploratory interest were observed in the mice. These data were confirmed through an alteration of normal behaviours, such as vertical lifting (rearing) and grooming, which began during the first week of infection. Moreover, these results correlated with alterations in body temperature. In the first week of infection, an increase in body temperature was observed (fever), which could be the cause of the decrease in spontaneous activity (Melo et al. 2010).

Food and water intake declined gradually during the first week of infection, which could be associated with the decrease in rearing (Siegfried et al. 2003); this characteristic behaviour of caged mice allows for feeding (among other activities) (Johnstone \& Higuchi 2001). The decrease in food and water consumption could also be due to the increased body temperature and cachexia (Emery 1999).

One study evaluating the involvement of molecules from Gram-negative bacteria in the promotion of sepsis showed that mice injected with outer membrane vesicles from Escherichia coli presented with clinically relevant symptoms, such as piloerection, eye exudates, hypothermia, tachypnea, leukopenia, hypotension and the systemic induction of tumour necrosis factor-alpha (TNF- $\alpha$ ) and interleukin-6 (Park et al. 2010).

A

$0 \mathrm{dp}$

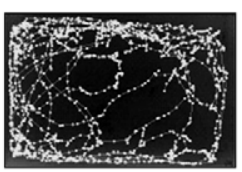

$7 \mathrm{dpi}$
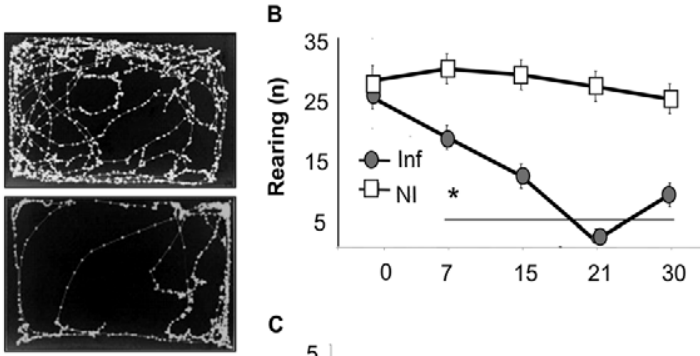

$15 \mathrm{dpi}$

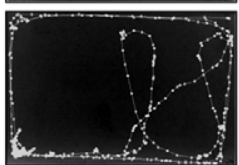

$21 \mathrm{dpi}$

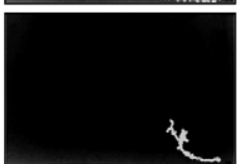

C

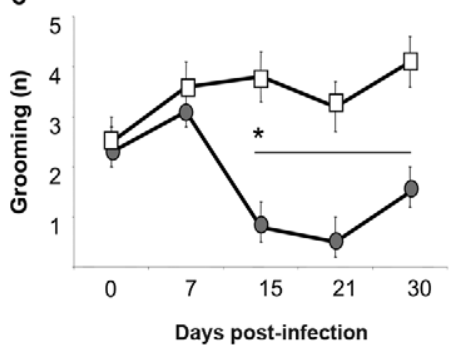

$30 \mathrm{dpi}$

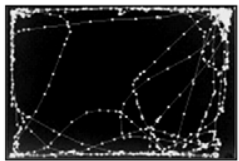

Fig. 4: behaviour and animal mobility. A: animal mobility was detected in a black arena recorded by the EthoVision XT6 system. The white spots represent the animal's position and the lines represent their displacement; B: rearing; C: grooming. NI [non-infected group (white squares)] showed no significant alterations during the 30 days of observation. Values correspond to means \pm standard deviation of three independent experiments performed with 10 mice each. Asterisk means statistically significant difference between infected and control mice $(\mathrm{p}<0.05)$. Inf (grey circles): Trypanosoma cruzi-infected group. 
Pro-inflammatory cytokines, especially TNF- $\alpha$, are associated with the development of cachexia (Silva et al. 2001, Porto 2010). Cachexia is characterised by the physical weakening of patients to a state of immobility stemming from appetite loss, asthenia and anaemia (Bossola et al. 2007, Lainscak et al. 2007). Tarleton (1988) suggested that $T$. cruzi-infected mice were primed for the production of TNF- $\alpha$ and referred to this cytokine as cachectin. Additionally, interferon- $\gamma$-activated macrophages produced TNF- $\alpha$ following $T$. cruzi infection, which suggests that TNF- $\alpha$ plays a role in both the amplification of nitric oxide production and parasite killing (Silva et al. 1995). In
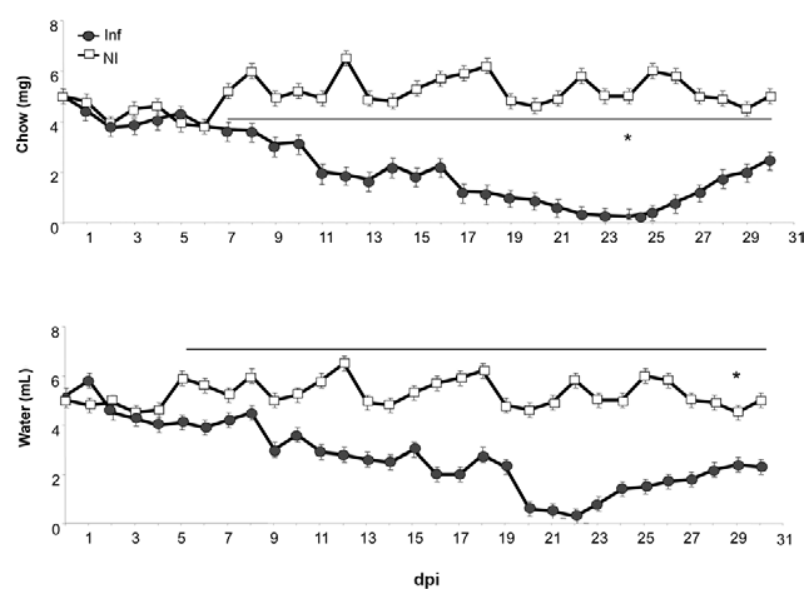

Fig. 5: food and water consumption. Estimation of the individual consumption of food and water during infection with Trypanosoma cruzi. A: T. cruzi-infected group [Inf (grey circles)] had inappetence (or anorexia) around 23-24 days post-infection (dpi); B: water intake was approximately 0 between 20-22 dpi. The non-infected group [NI (white squares)] showed no significant alterations during the 30 days of observation. Values correspond to means \pm standard deviation of three independent experiments performed with 10 mice each. Asterisk means statistically significant differences between infected and control mice $(\mathrm{p}<0.05)$.

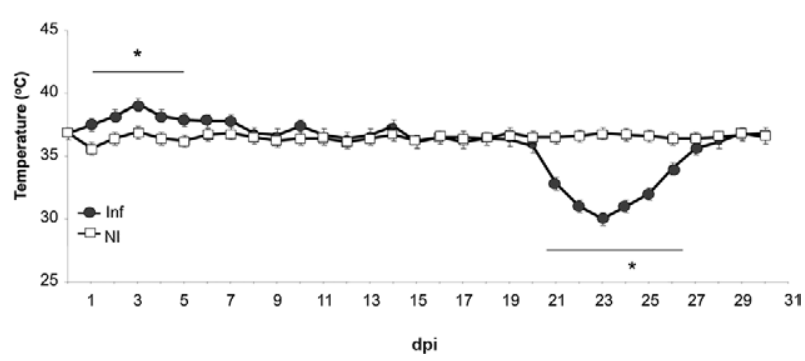

Fig. 6: body temperature. From 1-5 days post-infection (dpi), Trypanosoma cruzi-infected group [Inf (grey circles)] presented with hyperthermia. Between 21-26 dpi there was a sudden decrease in body temperature with the temperatures of the surviving mice returning to normal values at the end of the experiment ( $30 \mathrm{dpi})$. The non-infected group [NI (white squares)] showed no significant alterations during the 30 days of observation. Values correspond to means \pm standard deviation of three independent experiments performed with 10 mice each. Asterisk means statistically significant differences between infected and control mice $(\mathrm{p}<0.05)$. an experimental murine model of infection with $T$. cruzi, cachexia was reported to be caused by Chagas toxin (a molecule with similar characteristics to lipopolysaccharide). Mice given lethal doses of Chagas toxin became sluggish, stopped eating and drinking, dragged their hind legs, gradually developed both paralysis and breathing difficulties and died five-seven days after infection (Seneca 1969, Seneca \& Peer 1966).

In conclusion, the application of non-invasive methods is an effective way to evaluate and describe the clinical signs of mice during the course of an acute experimental infection with T. cruzi and these methods will be evaluated using other mouse lineages and parasite strains. Based on the parameters of physical activity (motor and exploratory activities), behaviour (rearing and grooming), food consumption and body temperature, it is possible to describe a murine model for Chagas disease with our results. The comparison of our results with those in the literature suggests that mice with acute T. cruzi infection have similar clinical signs to mice with toxaemia (sepsis).

\section{ACKNOWLEDGEMENTS}

To Dr Maria de Nazaré Corrêa Soeiro, head of the Laboratório de Biologia Celular (IOC/Fiocruz), for logistical support.

\section{REFERENCES}

Andrade SG, Campos RF, Sobral KS, Magalhães JB, Guedes RS, Guerreiro ML 2006. Reinfections with strains of Trypanosoma cruzi of different biodemes as a factor of aggravation of myocarditis and myositis in mice. Rev Soc Bras Med Trop 39: 1-8.

Araújo-Jorge TC 1989. The biology of Trypanosoma cruzi-macrophage interaction. Mem Inst Oswaldo Cruz 84: 441-462.

Araújo-Jorge TC, De Castro SL 2000. Questões da doença humana para trabalho em modelos animais. In TC Araújo-Jorge, SL de Castro, Doença de Chagas: manual para experimentação animal, Editora Fiocruz, Rio de Janeiro, p. 17-19.

Babad J, Geliebter A, DiLorenzo TP 2010. T-cell auto antigens in the non-obese diabetic mouse model of autoimmune diabetes. Immunology 131: 459-465.

Bates JH, Rincon M, Irvin CG 2009. Animal models of asthma. Am J Physiol Lung Cell Mol Physiol 297: 401-410.

Beltrão B, Cerroni P, Freitas R, Pinto Y, Valente C, Valente A, Costa G, Sobel J 2009. Investigation of two outbreaks of suspected oral transmission of acute Chagas disease in the Amazon Region, Pará state, Brazil, in 2007. Trop Doct 39: 231-232.

Bossola M, Pacelli F, Doglietto GB 2007. Novel treatments for cancer, cachexia. Expert Opin Investig Drugs 16: 1241-1253.

Brener Z 1962. Therapeutic activity and criterion of cure on mice experimentally infected with Trypanosoma cruzi. Rev Inst Med Trop Sao Paulo 4: 386-396.

Cerami A, Ikeda Y, Le Trang N, Hotez PJ, Beutler B 1985. Weight loss associated with an endotoxin-induced mediator from peritoneal macrophages: the role of cachectin (tumour necrosis factor). Immunol Lett 11: 173-177.

Chagas C 1909. Nova tripanozomiaze humana: estudos sobre a morfolojia e o ciclo evolutivo do Schizotrypanum cruzi n. gen., n. sp., ajente etiolojico de nova entidade morbida do homem. Mem Inst Oswaldo Cruz 1: 159-218.

Coura JR 2000. A doença de Chagas humana e seus modelos de estudo. In TC Araújo-Jorge, SL de Castro. Doença de Chagas: manual para experimentação animal, Editora Fiocruz, Rio de Janeiro, p. 19-24. 
Coura JR 2006. Transmission of chagasic infection by oral route in the natural history of Chagas disease. Rev Soc Bras Med Trop 39: 113-117.

Coura JR, Borges-Pereira J 2010. Chagas disease: 100 years after its discovery. A systemic review. Acta Trop 115: 5-13.

Cryan JF, Holmes A 2005. The ascent of mouse: advances in modelling human depression and anxiety. Nat Rev Drug Discov 4: 775-790.

Dias E 1934. Estudos sobre o Schizotrypanum cruzi. Mem Inst Oswaldo Cruz 28: 1-110.

Dias JC, Prata A, Correia D 2008. Problems and perspectives for Chagas disease control: in search of a realistic analysis. Rev Soc Bras Med Trop 41: 193-196.

Eickhoff CS, Lawrence CT, Sagartz JE, Bryant LA, Labovitz AJ, Gala SS, Hoft DF 2010. ECG detection of murine chagasic cardiomyopathy. $J$ Parasitol 96: 758-764.

Emery PW 1999. Cachexia in experimental models. Nutrition 15: 600-603.

Johnstone LE, Higuchi T 2001. Food intake and leptin during pregnancy and lactation. Prog Brain Res 133: 215-227.

Kalamarides M, Peyre M, Giovannini M 2010. Meningioma mouse models. J Neurooncol 99: 325-331.

Kalueff AV, Fox MA, Gallagher PS, Murphy DL 2007. Hypolocomotion, anxiety and serotonin syndrome-like behaviour contribute to the complex phenotype of serotonin transporter knockout mice. Genes Brain Behav 6: 389-400.

Keeney A, Jessop DS, Harbuz MS, Marsden CA, Hogg S, BlackburnMunro RE 2006. Differential effects of acute and chronic social defeat stress on hypothalamic-pituitary-adrenal axis function and hippocampal serotonin release in mice. $J$ Neuroendocrinol 18: 330-338.

Lainscak M, Podbregar M, Anker SD 2007. How does cachexia influence survival in cancer, heart failure and other chronic diseases? Curr Opin Support Palliat Care 1: 299-305.

Lapchik V, Mattaraia V, Ko G 2009. Cuidados e manejos de animais de laboratório, Editora Ateneu, São Paulo, 697 pp.

Lenzi H, Oliveira D, Lima M, Gattass CR 1996. Trypanosoma cruzi: paninfectivity of CL strain during murine acute infection. Exp Parasitol 84: 16-27.

Lescure FX, Le Loup G, Freilij H, Develoux M, Paris L, Brutus L, Pialoux G 2010. Chagas disease: changes in knowledge and management. Lancet Infect Dis 10: 556-570.

Marinho CR, D’Império Lima MR, Grisotto MG, Alvarez JM 1999. Influence of acute-phase parasite load on pathology, parasitism and activation of the immune system at the late chronic phase of Chagas disease. Infect Immun 67: 308-318.

Matsumoto K, Pinna G, Puia G, Guidotti A, Costa E 2005. Social isolation stress-induced aggression in mice: a model to study the pharmacology of neurosteroidogenesis. Stress 8: 85-93.

Melo ES, Barbeiro HV, Ariga S, Goloubkova T, Curi R, Velasco IT, Vasconcelos D, Soriano FG 2010. Immune cells and oxidative stress in the endotoxin tolerance mouse model. Braz J Med Biol Res 43: 57-67.
Moncayo A, Silveira AC 2009. Current epidemiological trends for Chagas disease in Latin America and future challenges in epidemiology, surveillance and health policy. Mem Inst Oswaldo Cruz 104 (Suppl. I): 17-30

Oliveira GM, Diniz RL, Batista W, Batista MM, Bani Correa C, Araújo-Jorge TC, Henriques-Pons A 2007. Fas ligand-dependent inflammatory regulation in acute myocarditis induced by Trypanosoma cruzi infection. Am J Pathol 171: 79-86.

Oliveira GM, Masuda MO, Rocha NN, Schor N, Hooper CS, AraújoJorge TC, Henriques-Pons A 2009a. Absence of Fas-L aggravates renal injury in acute Trypanosoma cruzi infection. Mem Inst Oswaldo Cruz 104: 1063-1071.

Oliveira GM, Silva T, Batista W, Franco M, Schor N 2009b. Acute Trypanosoma cruzi experimental infection-induced renal ischemic/reperfusion lesion in mice. Parasitol Res 106: 111-120.

Park KS, Choi KH, Kim YS, Hong BS, Kim OY, Kim JH, Yoon CM, Koh GY, Kim YK, Gho YS 2010. Outer membrane vesicles derived from Escherichia coli induce systemic inflammatory response syndrome. PLOS ONE 5: e11334.

Pavanelli WR, Gutierrez FR, Mariano FS, Prado CM, Ferreira BR, Teixeira MM, Canetti C, Rossi MA, Cunha FQ, Silva JS 2010. 5-lipoxygenase is a key determinant of acute myocardial inflammation and mortality during Trypanosoma cruzi infection. Microbes Infect 12: 587-597.

Porto CC 2010. Semiologia Médica, 5th ed., Editora Guanabara Koogan, Rio de Janeiro, 320 pp.

Schofield CJ, Jannin J, Salvatella R 2006. The future of Chagas disease control. Trends Parasitol 22: 583-588.

Seneca H 1969. Experimental toxaemia in mice due to chagastoxin. Trans R Soc Trop Med Hyg 63: 535-539.

Seneca H, Peer P 1966. Immuno-biological properties of chagastoxin (lipopolysaccharide).Trans R Soc Trop Med Hyg 60: 610-620.

Siegfried Z, Berry EM, Hao S, Avraham Y 2003. Animal models in the investigation of anorexia. Physiol Behav 79: 39-45.

Silva AC, Bezerra LM, Aguiar TS, Tavares D, Araujo LM, Pinto CE, Ribeiro OG 2001. Effect of genetic modifications by selection for immunological tolerance on fungus infection in mice. Microbes Infect 3: 215-222.

Silva JS, Vespa GN, Cardoso MA, Aliberti JC, Cunha FQ 1995. Tumour necrosis factor alpha mediates resistance to Trypanosoma cruzi infection in mice by inducing nitric oxide production in infected $\gamma$-interferon-activated macrophages. Infect Immun 63: 4862-4867.

Soeiro MNC, Dantas AP, Daliry A, Silva CF, Batista DGJ, Souza EM, Oliveira GM, Salomão K, Batista MM, Pacheco MGO, Silva PB, Santa-Rita RM, Barreto RFSM, Boykin DW, de Castro SL 2009. Experimental chemotherapy for Chagas disease: 15 years of research contributions from in vivo and in vitro studies. Mem Inst Oswaldo Cruz 104 (Suppl. I): 301-310.

Tarleton RL 1988. Tumour necrosis factor (cachectin) production during experimental Chagas disease. Clin Exp Immunol 73: 186-190.

Taylor TN, Greene JG, Miller GW 2010. Behavioural phenotyping of mouse models of Parkinson's disease. Behav Brain Res 211: 1-10. 